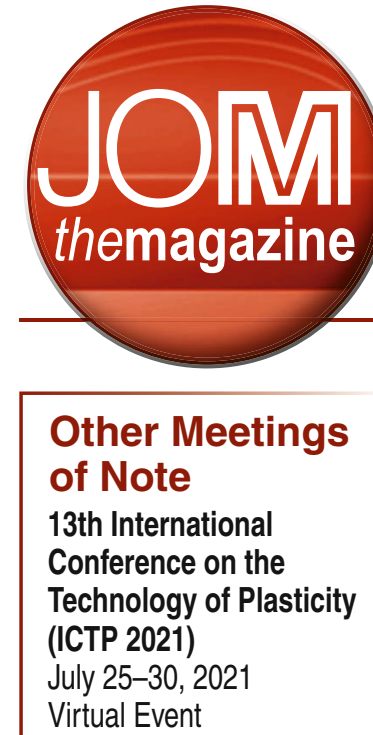

14th International Symposium on Superalloys (Superalloys 2021)

September 12-16, 2021

Seven Springs, Pennsylvania, USA

\section{Materials in Nuclear Energy Systems (MiNES 2021) September 19-23, 2021 Pittsburgh, Pennsylvania, USA}

Materials Science \& Technology 2021 (MS\&T21)

October 17-21, 2021

Columbus, Ohio, USA

Congress on Safety in

Engineering and Industry 2021

(Safety Congress 2021)

November 1-3, 2021

Fort Worth, Texas, USA

2nd World Congress on

High Entropy Alloys

(HEA 2021)

December 5-8, 2021

Charlotte, North Carolina, USA

Additive Manufacturing Benchmarks

(AM-Bench 2022)

August 15-18, 2022

Bethesda, Maryland, USA

Liquid Metal Processing and Casting Conference (LMPC 2022)

September 18-22, 2022

Philadelphia, Pennsylvania, USA

\title{
TMS meeting headlines
}

TMS is committed to your safety during the pandemic. Meeting dates and locations are current as of March 12, 2021. For the most recent updates on TMS-sponsored events, visit www.tms.org/Meetings.

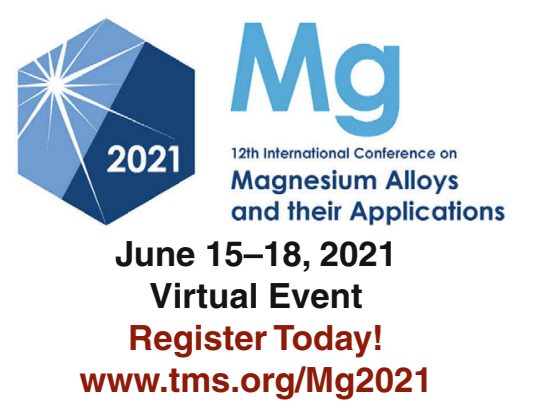

- The 12th International Conference on Magnesium Alloys and their Applications (Mg 2021) is a fully virtual event, featuring a mix of live and pre-recorded sessions. Registration includes access to all recorded sessions and proceedings content until June 30, 2021.

- The plenary speakers will include John Allison, University of Michigan; Michele Manuel, University of Florida; and Anil Sachdev, General Motors Company. The Mg 2021 program also includes a strong lineup of invited speakers and more than 140 contributed talks and posters scheduled during the event.

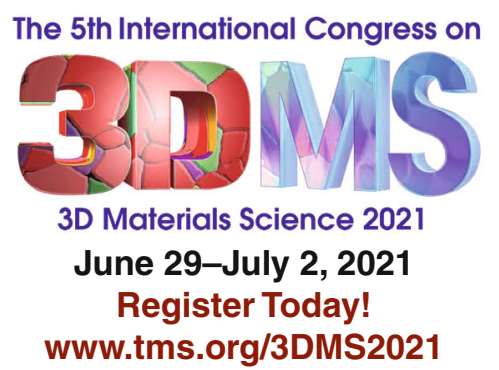

- Visit the 5th International Congress on 3D Materials Science (3DMS 2021) website for the confirmed slate of plenary and invited speakers at press time and to access the schedule-at-aglance, session sheets, and more details on the technical program.

- The TMS journal Integrating Materials and Manufacturing Innovation will be publishing a topical collection dedicated to the meeting. This collection will take the place of a traditional conference proceedings publication.

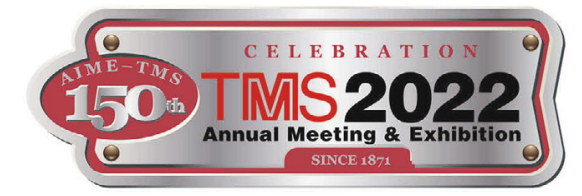

February 27-March 3, 2022 Anaheim, California, USA

Call for Abstracts Opens May 2021! www.tms.org/TMS2022

- The Fourth Summit on Diversity in the Minerals, Metals, and Materials Professions (DMMM4) will be colocated with the TMS 2022 Annual Meeting \& Exhibition (TMS2022). Access to this two-day event will be included with your TMS2022 registration.

- Make plans to join in the continued celebration of the 150th anniversary of TMS and the American Institute of Mining, Metallurgical, and Petroleum Engineers (AIME) at TMS2022.

\section{TIMS \\ First World Congress on ARTIFICIAL NTELLIGENCE MATERIALS \& MANUFACTURING 2022 April 3-6, 2022 Pittsburgh, Pennsylvania, USA Submit an Abstract by September 3, 2021 www.tms.org/AIM2022}

- The inaugural TMS World Congress on Artificial Intelligence in Materials and Manufacturing (AIM 2022) is the first event of its kind to focus on the role of artificial intelligence in materials science and engineering and related manufacturing processes.

- Abstracts are being considered now for inclusion in the technical program, including topics such as intelligent/ robotic manufacturing; machine learning/deep learning in materials and manufacturing; AI-assisted development of new materials/alloys; and more. Visit the congress website for more topics and to submit your work. 